\title{
The development and implementation of a Peer Assisted Learning programme at the University of Liverpool
}

\section{Gita Sedghi}

University of Liverpool, UK

\section{Trish Lunt}

University of Liverpool, UK

\section{Abstract}

A Peer Assisted Learning (PAL) programme was designed and implemented in the Department of Chemistry in the University of Liverpool during the 2012-13 academic year. The PAL programme was initially set up to support first year chemistry undergraduate students with one particular maths module but was extended to offer support to all Year 1 modules. The PAL programme was also designed to meet the needs of a second cohort of students, year 2 direct entry international students, but this paper focuses on the first year student programme.

A key element to the development of the Liverpool PAL programme was the contribution of student input throughout the initial programme design stages and, importantly, the ongoing involvement of students during the operation of the programme over the last three years. They provided evaluation and feedback on the programme's organisation and effectiveness, and were involved in subsequent discussions to analyse the data from these processes in order to improve and develop the programme. The concept of working with students as partners is not new, but it has risen in profile in recent years as highlighted by Healey et al. (2014) and many others. We believe that the PAL programme would not be as effective as it is without the ongoing involvement of students in all elements of the programme.

The paper will discuss the development and implementation of the PAL programme over the past three years, and highlight the value and importance of the role and contribution of 
the students in making the programme what it is today, as evidenced by the evaluation feedback from the students.

Keywords: Peer Assisted Learning; collaborative learning; student as partners.

\section{What is Peer Assisted Learning (PAL)?}

Peer Assisted Learning (PAL) is a student-to-student academic support scheme designed to typically benefit first year students. Student volunteers from higher levels are trained to become PAL leaders who facilitate group discussions which support academic topics but also learning strategies more generally. The role of the trained PAL leaders is not to teach, but one of facilitating collaborative learning.

The benefits of enhanced learning from students working in groups are well documented (Jacques and Salmon, 2007; and others), but one of the important features deliberately designed into the development of the Liverpool PAL programme was the ethos of working with the students as partners throughout all stages of the development and on an ongoing basis, beyond the traditional evaluation role.

\section{Developing the PAL programme at the University of Liverpool}

PAL was implemented in the Department of Chemistry in September 2012 after one year of research on various schemes at different higher education institutions. The aim of the programme was to develop a suitable scheme to support first year undergraduate students in adjusting to university life in general, and also to provide help with a specific maths module which is regarded as one of the most difficult subjects in the Chemistry degree programme (Becker and Towns, 2012). Evaluation of the first year maths course in the Department of Chemistry had identified a number of issues that students were struggling with, especially those without A level maths. These included lack of knowledge on how to approach problems from different angles, lack of confidence, lack of maths practice, and lack of assessment experience. While these issues were partially addressed at programme level via the changing of teaching delivery and assessment methods, it was believed that the PAL scheme could be used to enhance students' confidence in maths and to improve their skills on approaching problems from different angles. 
In addition, the PAL programme was intended to support international students, primarily a cohort from China entering directly into the second year of undergraduate studies in Liverpool. While language proficiency and culture is an acknowledged difficulty for international students in English-speaking universities (Andrade, 2006), a research project undertaken in 2010-11 within the Faculty of Science and Engineering at the University of Liverpool identified that Year 2 direct entry Chinese students were also unfamiliar with actual chemistry labs and the equipment used, which resulted in health and safety issues, as well as a loss of confidence. A related research project undertaken by Willis and Sedghi (2014) highlighted the support that the PAL programme could offer to international students with general key skills (e.g. laboratory skills) and practical skills (e.g. writing and presentation skills), two areas of particular difficulty for international students.

Initial research into various PAL programme models was funded by the National HE STEM programme. This funding enabled academic staff from the department to tailor the PAL programme developments to meet the specific requirements of the students at Liverpool. The programme was initially adapted from the model operated by Bournemouth University. Colleagues from the Universities of Sussex and Bradford were approached to act as critical friends during the initial programme development: one institution (Bradford) was at a similar initial stage, and the other (Sussex) had adapted a similar model a few years previously and was willing to share their learning.

Initial developments were also informed by focus groups comprising undergraduate students from the department. As well as providing valuable input, involving the students also helped them to recognise that the system was being designed to be run by students for students.

The PAL programme academic staff coordinator also attended a PASS (Peer Assisted Study Sessions - another name for PAL) training course delivered by the Teaching and Learning Support office at the University of Manchester, the UK national centre for such training. Attending the PASS training programme (which is recognised internationally as the UK benchmark) assisted the academic staff coordinator to understand, plan, implement, and evaluate the scheme, as well as offering guidance on the training of undergraduate students to become PAL leaders. Arendale (1994) gives a detailed introduction to the PASS model (also known as Supplemental Instruction (SI)). 


\section{Operationalising the PAL programme}

Four key roles have evolved for the Liverpool PAL programme:

- Academic staff coordinator - with overall responsibility for the programme in the department.

- PAL session leaders - students who volunteer to lead/facilitate specific PAL sessions.

- PAL subject leaders - a new role introduced in 2014-15. These are PAL session leaders who volunteer to take primary responsibility for coordinating materials to support a particular subject/topic and ensure appropriate materials are available for that subject for a particular session.

- PAL student coordinators - a new role introduced in 2014-15. This is a small team of Year 4 students who now organise and co-ordinate the PAL programme, assign the PAL leaders for the various sessions, and support them as required.

\section{Recruiting PAL leaders and co-ordinators}

Second year undergraduates (some of whom will have participated in sessions during their first year of studies) receive a short talk delivered by the academic staff coordinator and existing PAL leaders to introduce the PAL programme. Students interested in becoming a PAL leader are required to submit an application form which includes details of why they wish to become a PAL leader and the subjects that they would be willing to 'lead'. The academic staff coordinator will then review the academic performance of the students who have applied, particularly with respect to the subjects that they have offered to lead. When the new role of PAL student coordinator was introduced for the 2014-15 academic year, this was offered to a small team of existing trained PAL leaders.

\section{Promotion of the PAL programme to new students}

PAL is introduced to new students in a lecture given by the academic staff coordinator and an existing PAL leader during Welcome (Induction) Week. In week 1 of the new academic year, the PAL academic coordinator also delivers a separate introductory talk on study skills in university, and so this is another opportunity to promote the PAL programme. The week 1 study skills talk also highlights the importance of peer discussions and 
collaborative working as part of degree studies, a skill reinforced through the PAL sessions.

\section{Organisation of the PAL programme}

The PAL sessions take place for one hour every week, with a variety of subjects being covered during each session according to student demand. Although the sessions are not compulsory for new students, the PAL programme appears on student timetables. Organising the PAL sessions through the timetabling system ensures that the first year students are able to attend if they wish, and also that the second and third year PAL leaders are available to lead the sessions.

Another important element in the organisation of the programme is that all PAL session plans are uploaded into the 'Chemistry PAL' course on the University's Virtual Learning Environment (VLE), the online repository for all module information. All Year 1 students and PAL leaders are enrolled on to this course. PAL leaders are registered as instructors on the VLE so they can add to or amend PAL materials. All students need to access the VLE on a regular basis, so they become used to seeing the 'Chemistry PAL' course alongside the other modules they are studying.

The PAL sessions are held in a large seminar room which allows students to split into groups of typically 6-8 participants, with each group focusing on a specific subject or topic. Each group will be led by one or a pair of PAL leaders and there may be up to three different subjects/topics covered at each weekly session. Learning strategies and session activities are planned mainly by PAL subject leaders and the PAL leaders, with help from academic staff who lead the modules relevant to the subjects being covered at the PAL sessions.

Since 2014-15, the PAL student coordinators have organised the PAL session leaders and the subject leaders. They keep in regular contact with the academic coordinator to provide feedback on the scheme throughout the year and also assist in training new PAL leaders every academic year.

PAL sessions are typically attended by 8-10 PAL leaders who support approximately 40 first year students per session. When the PAL programme was first introduced in 2012-13, 
a booking system was implemented. This was found not to work due to significant numbers of students booking on to sessions and not turning up, leading to a number of session leaders, who had prepared materials, not being required. The booking scheme was therefore withdrawn after a year, but there was still the problem of how many leaders to assign and how to deal with unexpected numbers of applicants. For the 2013-14 academic year, there were occasions when there were more PAL leaders at the sessions than would be needed for an approximate ratio of 1:7. In these situations, PAL leaders would be paired up so they could all contribute. A gradual decrease in participant numbers over the whole academic year made it easier to predict how many leaders would be needed to cover each session.

In 2013-14, almost all Year 1 modules were supported by the scheme. Assigning one or two subjects to each session allowed each subject to be delivered every three weeks. However, this was found not to be ideal as students did not benefit from receiving continuous support on topics they were struggling with. In particular, students without $A$ level maths felt that they needed weekly maths sessions to discuss challenging topics related to the weekly workshops. In 2014-15, regular weekly PAL sessions were delivered specifically aimed at supporting students without A level maths, with one or two other subjects alongside the maths. Some subjects were delivered only during the revision period to enable regular sessions to be assigned to more challenging subjects.

\section{Evaluation}

Regular evaluation of the scheme has provided the opportunity to detect and resolve any issues, to identify areas for improvement, and to adapt the scheme to the needs of students, both the PAL 'beneficiaries' as well as the PAL leaders, as quickly as possible.

\section{Evaluating the PAL programme for beneficiaries (target students)}

Various methods are used to evaluate the PAL scheme at different times during an academic year. Online questionnaires consisting of both multiple choice and free text questions are administered at the end of every semester. In addition, the PAL student coordinators regularly liaise with PAL session leaders to gain more informal feedback, with mid-semester feedback collated via a questionnaire. The PAL student coordinators meet 
the academic coordinator regularly to discuss the feedback and decide if any immediate or longer term action is needed. The results of the end of semester surveys are also discussed as part of these meetings as appropriate. The students are therefore taking ownership of collating the regular feedback and also suggesting and implementing any action that may be required, with guidance from the academic coordinator as may be needed. Feedback from the end of year questionnaires also informs the following year's PAL leaders training sessions.

In addition to the questionnaires, focus groups have been organised with PAL beneficiaries for the last two years in order to gain more detailed evaluation evidence. Additional feedback also comes from staff- student liaison committee (SSLC) meetings.

\section{Evaluating the PAL programme for PAL Leaders}

The academic staff coordinator and the team of student coordinators organise at least two meetings during each semester with the PAL session leaders to gain formative feedback and discuss any issues that have arisen for them as PAL leaders. Leaders also complete end of year evaluation questionnaires which cover areas of the training they received, as well as organisational issues. Over the last two years, this questionnaire process has also been supplemented by focus groups.

\section{Results and discussion of evaluation outcomes from 2012-2015 Training of PAL leaders}

Feedback from the first training session for PAL leaders in preparation for the 2012-13 academic year programme highlighted a need for more specific training. The training programme for the 2013-14 academic year therefore included a range of short topics including the history of PAL, how to facilitate sessions without teaching, the benefits to both leaders and participants, the structure of the system, and how to plan the sessions. Another well-received development to the PAL leaders training session, which again resulted from student feedback, was the introduction of role plays delivered by experienced PAL leaders. 


\section{Materials and topics covered}

PAL leaders are asked regularly about the level of detail they would find helpful in terms of the materials prepared to support the PAL sessions by the PAL subject leaders. Not unexpectedly, there are a range of views, illustrated by these typical responses:

The scripts didn't seem that necessary. I would have rather if they just came to me and asked us questions that they needed answering, rather than the questions we wanted them to need to answer.

It would be really handy tutorial stuff, at least then we could send them in advance, we'd have the answers, we'd be able to sit through and just say, 'we've got some questions that are pre-prepared, can we have a look at them'. Because I remember, in the first PAL session which was maths, we had to make up questions at the time for them, and that's not easy.

Year 1 student representatives in the SSLC were supportive of having detailed session plans as they would bring 'more structure to the PAL sessions'. Therefore, it was decided that session plans would be prepared to cover the various subjects to support the PAL leaders as needed.

Evaluation of the PAL programme in 2013-14 highlighted additional issues associated with a particular subject only being discussed every 2-3 weeks. The PAL leaders did not find the gaps between the specific subjects helpful (a finding which was also reported by the PAL beneficiaries) and so it was decided to cover the less challenging subjects only near the exam period in order to allow more regular sessions with the more challenging subjects.

\section{Organising and assigning PAL leaders}

Another issue arising in 2013-14 was poor attendance of some PAL leaders which resulted in poorly organised sessions. These frequent absences highlighted the requirement of a system to deal with such a situation if it happened, or ideally to prevent it happening in the first place. The solution to this problem came from feedback from PAL leaders who suggested that the new post of PAL student coordinators be developed, with a role to ensure that sessions were planned and covered by prepared PAL leaders. The leaders 
suggested that a coordinator would be in charge of each topic (e.g. 'organic', 'inorganic'); coordinators would have the lists and contact details of all the PAL leaders in that topic; they would lead the planning to make sure everyone had a chance to give input; and they would then e-mail the plan to everyone after the planning meeting.

This was an interesting solution proposed by the students as it had the potential for significant tensions, since students would have to take on an authority role with fellow students. However, for the 2014-15 academic year, these discussions with the students resulted in the creation of two new roles: PAL subject leaders and PAL student coordinators. PAL subject leaders would take on the role of planning the sessions and preparing session plans for their subject of interest. They would take the lead on the related subject and get help from the academic module leaders and other PAL leaders if required. The PAL coordinators would help in assigning leaders to different subjects, communicating between leaders and participants, resolving difficulties, organising meetings with leaders, and supervising the sessions.

\section{Benefits for PAL leaders and coordinators}

Evaluation with PAL leaders highlights that the programme has helped them to enhance their employability and communication skills. Providing session plans and facilitating group discussions for Year 1 students has also deepened their understanding of the subject studied. As one student said:

When we first started university, we were quite shy, finding it difficult to approach lecturers for help. Now we have the confidence to lead group discussion, whilst also teaching 1st Year students how to become more independent learners. This has really enhanced our career prospects, whether it be for a career in teaching or more generally through the communication and organisation skills we have acquired.

At the end of the 2014-15 academic year, some additional evaluation was conducted with the three Year 4 students who had taken on the new role of PAL student coordinator to ascertain what they felt they had gained from being both PAL leaders and PAL student coordinators. They were interviewed as a group. All three students had (typically) coordinated about 15-20 PAL sessions over the three years that they were PAL leaders, with their 2014-15 role involving coordination of the whole programme. During 2014-15, these 
three students typically devoted a minimum of 3-5 hours per week to the PAL programme, with one also being captain of the university basketball team, and another a student course representative, additional roles which also needed time and commitment. The third coordinator spent in excess of 5 hours/week supporting the PAL programme. In addition, all three students were involved with supporting other department activities such as Open Days, amounting to another ten days or so over the year.

Asked what motivated them initially to volunteer as PAL leaders, typical responses included 'I saw it as an opportunity to build my confidence' and 'It could provide evidence to support a possible future career as a teacher'. When asked to describe what they believed they had gained from their involvement in the programme, all three talked about the development in 'confidence' and 'self-confidence' and about being able to 'speak in front of a group... which was something I couldn't have done two years ago'.

Two students also mentioned that undertaking the coordination role had 'helped to develop their people skills'. For example, they had had to deal with students 'who had been trained as PAL leaders, didn't turn up to their sessions, and then turn up again and expect to run a session'. Resolving such situations had needed patience, tact, and organisation, both in dealing with less reliable PAL leaders who also were fellow students, and also in organising the sessions and materials/worksheets with the PAL leaders who were able to attend to run the sessions. The following quotes illustrate their learning and the perspective that they brought as student organisers:

It was important that we understood the problems that some PAL leaders were having which resulted in them not being able to attend some sessions; we needed to understand where they were coming from, and to talk to them on their level, but also explain the situation from our point of view.

We also had to learn to be firm early on so that we didn't waste the time of the PAL leaders or the students who had come to the sessions.

One student also talked about the transferability of organisational skills to and from her role in organising the basketball team, and the importance of 'learning how to suggest changes in a professional manner'. In terms of more subject-based learning, all three 
students talked about how running PAL sessions provided an opportunity to 'revise and reaffirm knowledge, from Year 1 through to Year 3'.

\section{Benefits for PAL beneficiaries (target students)}

The end of semester evaluations of PAL in 2012-14 showed that student participants found PAL sessions very useful in adapting to university life and assisting them with the challenging modules and topics:

With the help of the PAL Leaders, I got advice and support I needed to understand and structure my studies. They offered tips and explanations on some topics I initially struggled with and set me on the right path.

I used to have a problem with getting help when I was younger because I was embarrassed. But I have attended a few PAL sessions and they have been very useful and it made me comfortable with getting help.

The following results are taken from the end of (2014-15) year online questionnaire that was sent to all first year chemistry students; 45 responses were received (which represents approximately $17 \%$ of the student cohort).

When asked what encouraged them to attend the PAL sessions, $91 \%$ of respondents mentioned the fact that the sessions were timetabled. This is an interesting finding: as mentioned earlier, the PAL sessions are optional for first years, but the fact that they are included on the timetable (which was purely for logistical reasons) had an impact on the students.

Other key findings from the survey included: $25 \%$ of respondents attended because they were 'struggling with their course'; $16 \%$ of respondents cited 'lack of confidence with studying at university'. 58\% of respondents attended the PAL sessions regularly/weekly with the top four reasons cited for this being usefulness of talking to students who had already completed Year 1, the opportunity to clarify basic concepts, help with understanding course subject matter, and gaining an awareness of course expectations. 
Following the analysis of the questionnaire, a group of ten first year students attended a focus group to probe some of the questionnaire responses in more depth. The students gave a variety of responses to what motivated them to attend the PAL sessions initially: 'It was on our timetable so I thought we had to go'; 'I didn't want to miss out'; and 'I thought l'd try them to see if they were useful'.

Some had also heard from some second year students that they had been very useful in supporting learning. As the questionnaire results indicate, many students continued to attend the sessions and so students were asked what encouraged them to continue to participate. Typical responses included 'it is easier to talk to a second year student sometimes than the lecturer' and 'the PAL leaders can sometimes help to 'make things easier' the way they explain things'.

Some students further commented that they preferred to stay with the same PAL leaders and that this influenced their choice of PAL sessions and groups. They talked about 'staying with someone they knew and trusted', and 'someone whose support style was meeting their needs'. An additional comment was that the students felt that they could 'go more in depth' with someone they knew. Again, the importance and value of support from peers is demonstrated in these responses.

Asked if they would recommend the PAL sessions to other new first year students, typical comments included 'it's worth going to hear the experiences of the second year students and the focus of their revision topics'; 'it builds your confidence'; and 'they are reassuring'. It is clear from these comments that the first year students had valued the learning they were receiving from the PAL sessions, but also that the learning environment and the opportunity to engage with the students from a higher year group was a significant contribution to their learning experience.

From a wider perspective, PAL recipients also have the potential to develop skills of communication (through communicating the difficulties they are having), teamwork (through working and sharing their thoughts with other students in the PAL groups), as well as learning about themselves through the act of supporting others with their learning. 
The department perspective: some general trends over the three years of the PAL programme

Figure 1 shows the increase in number of applications received from Year 2 and 3 chemistry students who were interested in becoming PAL leaders in each academic year. In the first year of PAL implementation (2012-13), both Year 2 and Year 3 students were invited: from 2013, applications have only been invited from Year 2 students, with numbers increasing every year.

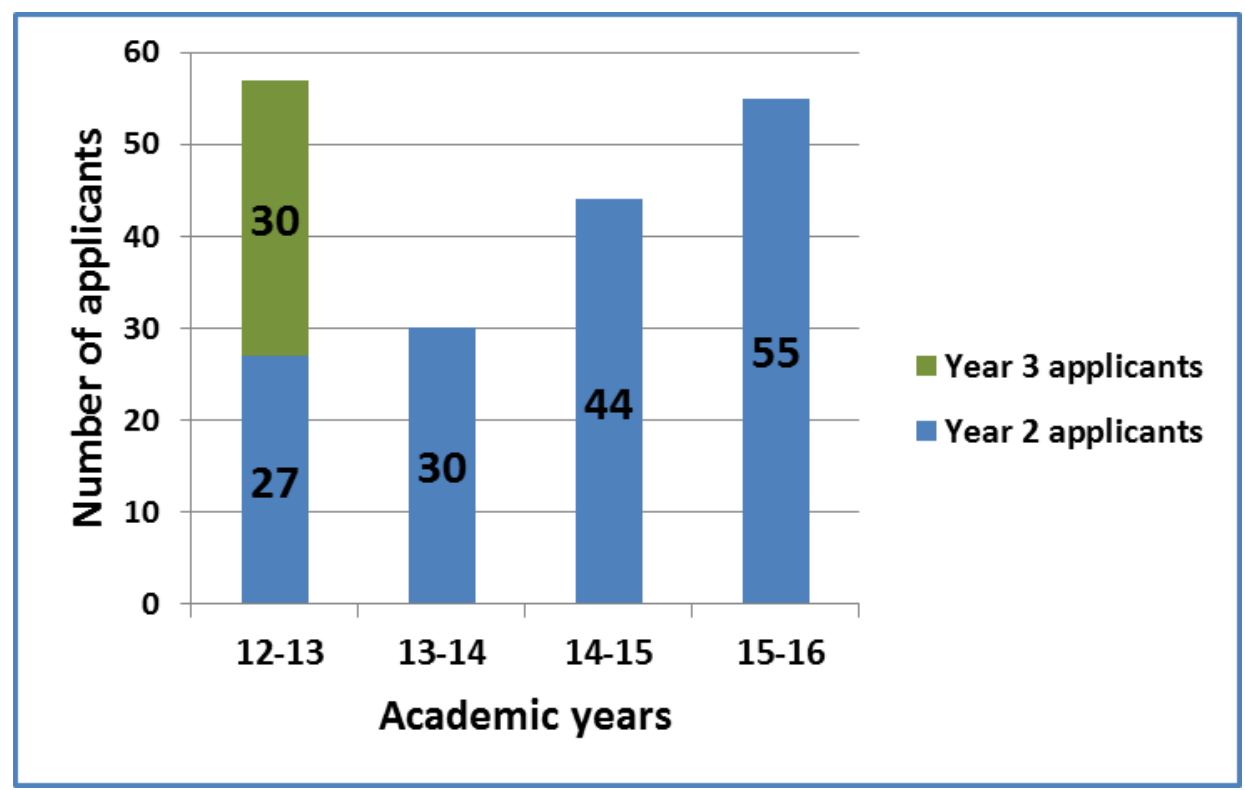

Figure 1. Number of applications from students to become PAL leaders.

This is itself a positive indicator of students who have perhaps valued the PAL sessions as student beneficiaries but who are also sufficiently engaged to be prepared to give something back to other students in their departments.

Figure 2 shows the increasing number of Year 1 students attending the PAL programme over the past three years, perhaps another indicator of the value of the programme spreading by word of mouth. 
Figure 2. Increase in number of Year 1 participants over past three years.

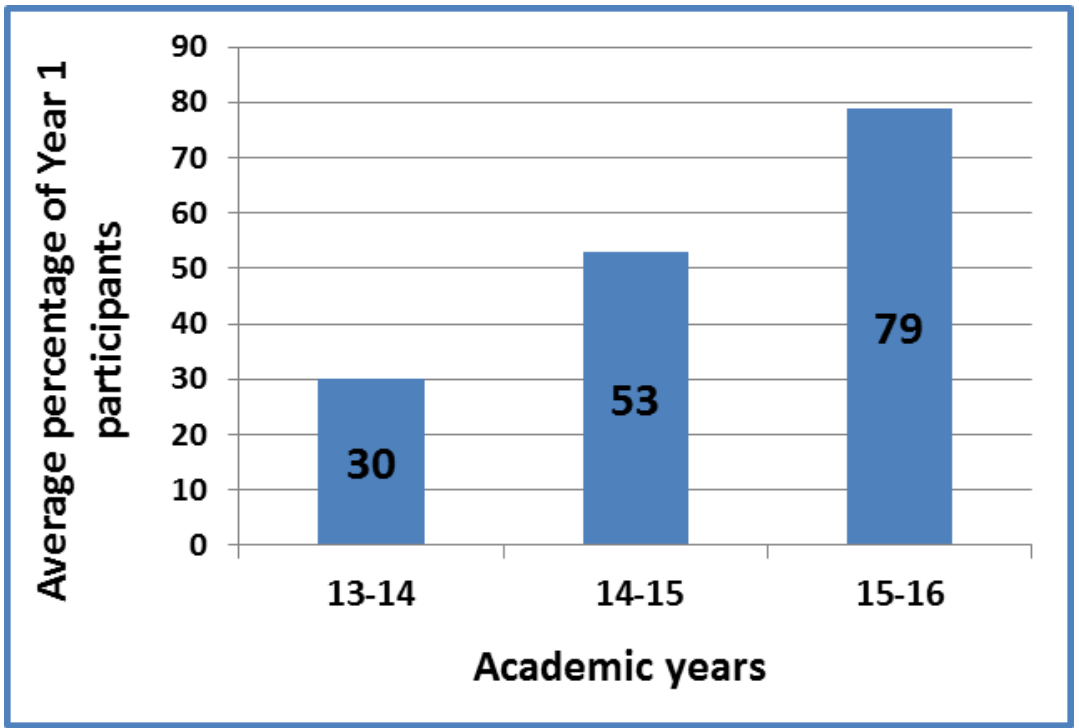

\section{Summary}

There are many benefits of PAL to the recipients. In terms of supporting subject learning, the PAL leaders tend to be quite close in age to the first year students. The evaluation comments highlighted that the first year students saw the PAL leaders as more approachable, but also perhaps more understanding of the difficulties that they were facing, having been in the same position only 12-24 months previously.

PAL sessions can also offer additional feedback opportunities from peers and PAL leaders, as well as offering a different learning environment to the one in which the subject was originally covered, which could be advantageous to some students. Both PAL leaders and beneficiaries can also benefit substantially as highlighted by their evaluation comments about the sessions reinforcing and reaffirming their learning.

There are arguably also wider benefits to the institution. PAL is a beneficial student engagement programme that can support the critical phase of transition into higher education. Kandiko and Mawer (2013) recommend implementing intervention strategies to support this crucial phase. Research by Chickering and Gamson (1987), Kuh (1995; 2009) and many others demonstrates a positive relationship between students engaging in a range of activities and their student experience. 
As Kuh (2009, p.698) noted:

Student engagement and its historical antecedents - time on task, quality of effort, and involvement - are supported by decades of research showing positive associations with a range of desired outcomes of college.

PAL programmes provide one such educational opportunity that can benefit all participants and reinforce the role of 'students as partners' - in this case, as partners in the design of the learning, as well as partners in implementing and supporting learning of other students.

Lessons have also been learned from an organisational point of view. The fact that the programme information is set up as a 'module' in the institution's VLE, so appearing alongside all credit-based modules, perhaps reinforces its 'academic standing' but also has the benefit of the information relating to students' studies all being in the same place, as well as providing the opportunity for communication between PAL leaders and first year students. It has also proved important that the scheme is tailored and structured to support particular learning needs from specific modules, and that the individual sessions are well organised from the perspective of both the PAL leaders and the PAL beneficiaries.

Arguably, the most important element to the successful sustainability and development of this programme has been the continuous involvement of the students in the planning and development of the PAL programme, a key element in fostering ownership and ensuring that the programme is tailored to the needs of the students, the discipline and the department.

\section{Acknowledgements}

The authors would like to acknowledge the support and contribution of all the students who contributed to the research studies/development of the PAL programme and, in particular, to the first group of PAL student coordinators. The authors would also like to acknowledge the support received from the national HE STEM programme. 


\section{References}

Andrade, M.S. (2006) 'International students in English-speaking universities', Journal of Research in International Education, 5(2), pp. 131-154.

Arendale, D. (1994) 'Understanding the Supplemental instruction (SI) model', New Directions for Teaching and Learning, 60(4), pp. 11-22.

Becker, N. and Towns, M. (2012) 'Students' understanding of mathematical expressions in physical chemistry contexts: an analysis using Sherin's symbolic forms', Chemistry Education Research and Practice, 13(3), pp. 209-220.

Chickering, A.W. and Gamson, Z.F. (1987) 'Seven principles for good practice in undergraduate education', AAHE Bulletin, 39(7), pp. 3-7.

Healey, M., Flint, A. and Harrington, K. (2014) Engagement through partnership: students as partners in learning and teaching in higher education. Available at: https://www.heacademy.ac.uk/engagement-through-partnership-students-partnerslearning-and-teaching-higher-education (Accessed: 12 August 2015).

Jaques, D. and Salmon, G. (2007) Learning in groups. $4^{\text {th }}$ edn. London: Routledge.

Kandiko, C.B. and Mawer, M. (2013) Student expectations and perceptions of higher education. London: King's Learning Institute.

Kuh, G.D. (1995) 'The other curriculum: out-of-class experiences associated with student learning and personal development', Journal of Higher Education, 66(2), pp. 123155.

Kuh, G.D. (2009) 'What student affairs professionals need to know about student engagement', Journal of College Student Development, 50(6), pp. 683-706. 
Willis, I. and Sedghi, G. (2014) 'Perceptions and experiences of home students involved in welcoming and supporting direct entry 2nd year international students', Practice and Evidence of Scholarship of Teaching and Learning in Higher Education, 9(1), December 2014, pp. 2-17.

\section{Author details}

Gita Sedghi is a lecturer in the Department of Chemistry, University of Liverpool. She is passionate about teaching and active in researching her own practice for the enhancement of student learning. She was awarded HEA funding to undertake research in the areas of internationalisation and peer assisted learning which led to her implementing a peer assisted learning programme in her department which she continues to run successfully. Further, she was awarded HEA funding to create pre-lab activities which resulted in a series of videos, photos and online assessments across first and second year undergraduate lab courses.

Trish Lunt is an Educational Developer in the Centre for Lifelong Learning at the University of Liverpool. She contributes to the CPS and PG Cert programmes run by the department, and leads a team dedicated to increasing student access to and take-up of co- and extracurricular activities, alongside developing an ePortfolio system for the institution that will support students in recognising the achievements and skills gained from these extracurricular activities. She has long standing areas of interest in researching and developing activities that support the student experience, such as peer mentoring, peer assisted learning, group-work, and the field of student engagement in general. 